\title{
Comparative study of the acute effects of two ways of myofascia release on biceps femoris and semitendinosus muscles after a romanian deadlift exercise
}

\section{Opinion}

As therapists we are used to have clinical evidence of health improvement after myofascial releas etherapy. Nevertheless, the scientific evidence of the application of the myofascial release therapy is scarce. ${ }^{1-6}$ Since is complicated to objectify the effects of the therapy and there are different ways to apply it. Nowadays, there are also a numerous ways with different tools to self-release the myofascia after physical exercise that have not been proven enough to be effective. Therefore, in order to know more about the effectiveness of this applications and using our experience with the Tesiomyography to evaluate the mechanical characteristics of the muscles through a transversal electrical stimulus and all that is known about the physiological characteristics of the fascia.The purpose of this study was to compare the acute effects of the use of the Roller Foam and Crossed Hands Technique (Myofascial Therapy) on the mechanical characteristics of bíceps femoris (BF) and semitendinosus (ST) muscles of the dominant leg son after a Romanian deadlif texercise.

Thirty-four ( $\mathrm{n}=34$ ) subjects (age: $24.52 \pm 3.12$ years old) students of Physical Education of the University of Las Palmas de Gran Canaria were evaluated. They were divided into three groups: Roller Foam Group (RG, n=10); Crossed Hands Technique Group (CHG, n=15) and Control Group (CG, n=9). The Tensiomyography (TMG) were used to evaluate the mechanical characteristics of the bíceps femoris and semitendinosus muscles. Specifically, the Radial Displacement of the muscles' bellies (Dm) and Contraction Time (Tc) were measured. The measures were taken: in basal conditions; after a $5 \mathrm{~min}$ of continuos run $(8 \mathrm{~km} / \mathrm{h})$ warming up; after a Romanian deadlift with growing loads of the 1RM: (50\%/15 reps, $60 \% / 10 \mathrm{reps}, 70 \% / 8 \mathrm{reps}$, $80 \% / 6$ reps, $90 \% / 3$ reps), with $2 \mathrm{~min}$ rest between each load set; five and ten minutes after the exercise. The myofascial release applications were just after the first five minutes of rest (Figure 1).

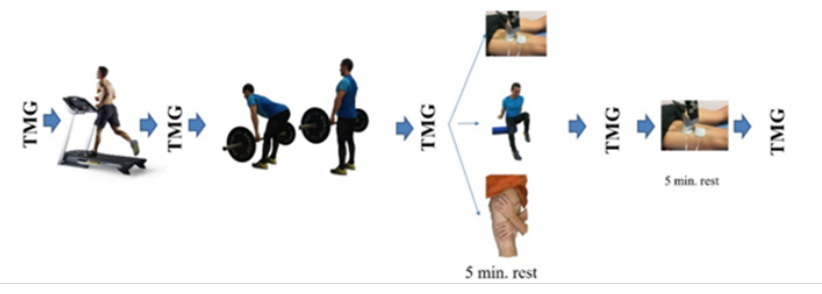

Figure I Protocol process.

Statistically significant differences $(\mathrm{p} \leq 0.05)$ were found for Dm in the ST of the CHG. Those differences were kept during the whole rest time. This recovery also was registered in the CG for the first 5 min rest ( $\mathrm{p} \leq 0.05)$, but not in the last 5 min rest. And RG did not experienced any significant difference. On the other hand, none of the groups got significant changes in BF. However, for Tc only the GM
Volume I Issue 2 - 2017

\author{
Suarez Rodriguez Vidina, Rodriguez Ruiz \\ David \\ Departament of Physical Education, University of las palmas de
} Gran Canaria, Spain

Correspondence: Rodriguez Ruiz David, Departament of Physical Education, University of Las Palmas de Gran Canaria (ULPGC), Spain, Email david.rodriguezruiz@ulpgc.es

Received: May 26, 2017 | Published: June 02, 2017

could come back to the basal values during the recovering process for both muscles, both after $5 \mathrm{~min}$ and after $10 \mathrm{~min}$ (Figure 2).
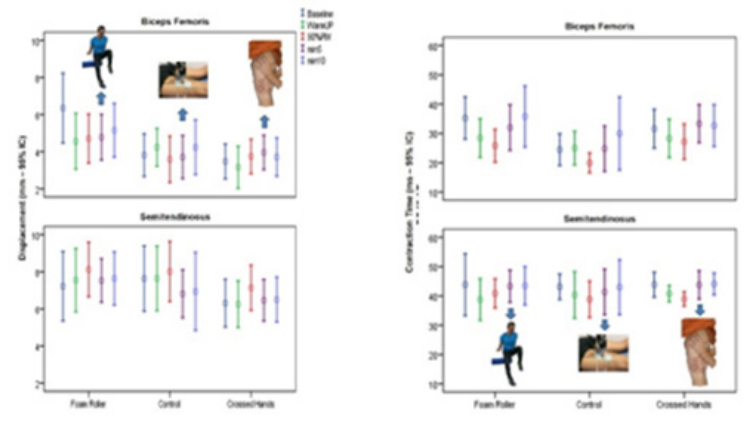

Figure 2 Mean on the mechanical parameters (máximum muscle belly radial displacement - Dm and contraction time - Tc) of the muscles (BF and ST) along all the protocol for different groups.

Considering collagen as the main component of the fascial tissue, is important that it has an appropriate orientation of its fibres. This orientation depends on the suitable pressure and movement. If they are not suitable, pathological cross-linking starts to form, which increases tissue's thickness and decreases movement. Therefore, movement is essential for the correct orientation of the collagen fibres and to prevent retractions and adherences of the tissue. Main fascial tissue's properties are tensegrity, -balance between tension and compression-; and piezoelectricity, -difference of voltage caused by the muscular stretching which compress the fascial tissue. This tissue has an integrated electronic network. If this network is kept correctly, fascial characteristics- elasticity, flexibility, elongation and resistanceare kept. ${ }^{7}$

When there is a trauma in the fascial tissue such as muscular fatigue, movement is not enough to facilitate the recovery. Therefore, therapy is necessary. Miofascial Therapy has various forms of application. 
One of them, is crossed hands technique. We use the hands to apply some amount of pressure and compression to the tissue in order to harmonize the imbalances between compression and tension. And to recover the normal biological electric currents.

The results got in the CHG agree well with Haas et al. ${ }^{8,9}$, Crawford et al. ${ }^{10}$ in their work on rabbit's musculature after an eccentric exercise, causing greater reduction in neutrophil and macrophage infiltration of the exercised muscle, increasing recovery of mechanical properties and showed histological evidence.

On the other hand, individual differences and self-application of the Roller Foam may have influenced the results, as Beardsley et al. ${ }^{3}$, Cheatham et al. ${ }^{4}$ suggest in their respective revisions. Still, research about the use of Roller Foam in muscular recovery is aimed in the disappearance of the acute muscular pain or after various times. ${ }^{11-13}$ which increases arterial function, ${ }^{14,15}$ through cortisol level's modulation. ${ }^{16}$

With these results, we can conclude that in our study the muscular recovery is better after the application of the crossed hands technique.

\section{Acknowledgements}

\section{None}

\section{Conflict of interest}

The author declares no conflict of interest.

\section{References}

1. Couture G, Karlik D, Glass SC, et al. The Effect of Foam Rolling Duration on Hamstring Range of Motion. The open orthopaedics journal. 2014;9:450-455.

2. Healey KC, Hatfield DL, Blanpied P, et al. The effects of myofascial release with foam rolling on performance. The Journal of Strength \& Conditioning Research. 2014;28(1):61-68.

3. Cheatham SW, Kolber MJ, Cain M, et al. The effects of self-myofascial release using a foam roll orroller massager on joint range of motion, muscle recovery, and performance: a systematic review. International Journal of Sports Physical Therapy. 2015;10(6):827-838.

4. Beardsley C, Skarabot J. Effects of self-myofascial release: A systematic review. Journal of Bodywork and Movement Therapies. 2015;19(4):747758.
5. Schroeder AN, Best TM. Is self myofascial release an effective preexercise and recovery strategy? A literatura review. Current Sports Medicine Reports. 2015;14(3):200-208.

6. DeBruyne DM, Dewhurst MM, Fischer KM, et al. Self-Mobilization Using a Foam Roller Versus a Roller-Massager: Which is More Effective for Increasing Hamstrings Flexibility?. Journal of sport Rehabilitation. 2016;26(1):94-100.

7. Pilat A. Terapias miofasciales: Inducción miofascial. Aspectos teóricos y aplicaciones clínicas. Madrid: McGraw-Hill-Interamericana; 2003.

8. Haas C, Butterfield TA, Abshire S, et al. Massage timing affects post exercise muscle recovery and inflammation in a rabbit model. Medicine and Science in Sports and Exercise. 2103;45(6):1105-1112.

9. Haas C, Butterfield TA, Zhao Y, et al. Dose-dependency of massage-like compressive loading on recovery of active muscle properties following eccentric exercise: rabbit study with clinical relevance. British Journal of Sports Medicine. 2013;47(2):83-88.

10. Crawford SK, Haas C, Butterfield TA, et al. Effects of immediate vs. Delayed massage-like loading on skeletal muscle viscoelastic properties following eccentric exercise. Clinical Biomechanics. 2014;29(6):671678.

11. MacDonald GZ, Button DC, Drinkwater EJ, et al. Foam rolling as a recovery tool after an intense bout of Physical activity. Med Sci Sports Exerc. 2014;46(1):131-142.

12. Jay K, Sundstrup E, Sondergaard S.D, et al. Specific and crossovereffects of massageformusclesoreness: randomized controlled trial. Int $J$ SportsPhysTher. 2014;9(1):82-91.

13. Pearcey GEP, Bradbury-Squires DJ, Kawamoto JE, et al. Foam Rolling for Delayed-Onset Muscle Soreness and Recovery of Dynamic Performance Measures. J Athl Train. 2015;50(1):5-13.

14. Arroyo-Morales M, Olea N, Martinez M, et al. Effects of myofascial release after high-intensity exercise: a randomized clinical trial. $J$ Manipulative Physiol Ther. 2008;31(3):217-223.

15. Okamoto T, Masuhara M, Ikuta K. Acute effects of self-myofascial release using a foam roller on arterial function. J Strength Cond Res. 2014;28(1):69-73.

16. Kim K, Park S, Goo B, Choi S. Effect of self-myofascial release on reduction of physical stress: a pilot study. $J$ Phys Ther Sci. 2014;26(11):1779-1781. 